\title{
Genetic Variability Based on Tandem Repeat Numbers in a Genomic Locus of 'Candidatus Liberibacter asiaticus' Prevalent in North East India
}

\author{
Yanglem Herojit Singh ${ }^{1}$, Susheel Kumar Sharma (D) ${ }^{2 *}$, Bireswar Sinha ${ }^{1}$, Virendra Kumar Baranwal, \\ N. Bidyananda Singh ${ }^{2}$, Ngathem Taibangnganbi Chanu, ${ }^{2,4}$, Subhra S. Roy ${ }^{2}$, Meraj A. Ansari', \\ Arati Ningombam ${ }^{2}$, Ph. Sobita Devi ${ }^{1}$, Ashis Kumar Das ${ }^{5}$, Salvinder Singh ${ }^{6}$, K. Mamocha Singh $^{7}$, \\ and Narendra Prakash ${ }^{2}$ \\ ${ }^{1}$ Department of Plant Pathology, College of Agriculture, Central Agricultural University, Imphal 795004, India \\ ${ }^{2}$ ICAR Research Complex for NEH Region, Manipur Centre, Imphal 795004, India \\ ${ }^{3}$ Advanced Centre for Plant Virology, Division of Plant Pathology, ICAR-Indian Agricultural Research Institute, New \\ Delhi 110012, India \\ ${ }^{4}$ College of Horticulture and Forestry, Central Agricultural University, Pasighat 791102, India \\ ${ }^{5}$ ICAR-Central Citrus Research Institute, Nagpur 440010, India \\ ${ }^{6}$ Department of Agricultural Biotechnology, Assam Agricultural University, Jorhat 785013, India \\ ${ }^{7}$ Department of Entomology, College of Agriculture, Central Agricultural University, Imphal 795004, India
}

(Received on March 21, 2019; Revised on August 23, 2019; Accepted on September 5, 2019)

The genetic variability of 'Candidatus Liberibacter asiaticus' (CLas) population associated with huanglongbing (HLB) disease of citrus in North Eastern (NE) region of India, a geographically locked region, and home for the diversity of many citrus species was analyzed on the basis of tandem repeat numbers (TRN) in variable CLIBASIA_01645 genomic loci. Fifty-five CLas strains sampled from different groves of NE Hill (NEH) region of India were in single amplicon group, but there was remarkable genetic variability in TRNs. The TRN in HLB-associated CLas strains varied from 0-21 and two novel repeat motifs were also identified. Among the NE population of CLas, TRN5 and TRN9 were most frequent (total frequency of $36.36 \%$ ) followed by TRN4 (14.55\%) and TRN6, TNR7 with a frequency of $12.73 \%$ each. Class II type CLas genotypes $(5<$ TRN $\leq$

\footnotetext{
*Corresponding author.

Phone) +91-385-2414654, FAX) +91-385-2414260

E-mail) susheelsharma19@gmail.com

ORCID
}

Susheel Kumar Sharma

https://orcid.org/0000-0002-9114-4231

(c) This is an Open Access article distributed under the terms of the Creative Commons Attribution Non-Commercial License (http:// creativecommons.org/licenses/by-nc/4.0) which permits unrestricted noncommercial use, distribution, and reproduction in any medium, provided the original work is properly cited.

Articles can be freely viewed online at www.ppjonline.org.
10) had highest prevalence (frequency of $60.00 \%$ ) in the samples characterized in present study. Class I (TRN $\leq 5)$ genotypes were second highest prevalent $(29.09 \%)$ in the NEH region. Further analysis of genetic diversity parameters using Nei's measure ( $\mathrm{H}$ value) indicated wide genetic diversity in the CLas strains of NE India (H value of 0.58-0.86). Manipur CLas strains had highest genetic variability (0.86) as compared to Eastern, Southern and Central India. The $R_{10}$ values (TRN $\leq$ 10/TRN > 10) of NE CLas population was 10.43 (73/7), higher from other regions of India. Present study conclusively reported the occurrence of high genetic variability in TRN of CLas population in North East Indian citrus groves which have evolved to adapt to the specific ecological niche.

Keywords : 'Candidatus Liberibacter asiaticus', CLIBASIA_01645 locus, huanglongbing, North East India, tandem repeat number

Handling Editor : Sohn, Kee Hoon

Greening ("huanglongbing", HLB) is most destructive disease of citrus causing major economic losses to citrus industry worldwide including India (Ahlawat, 1997; Bové, 2006; Ghosh et al., 2015). From the citrus growing areas of India, the disease was confirmed by transmitting it through 
Asian citrus psyllid during 1967 (Capoor, 1963; Capoor et al., 1967). Association of 'Candidatus Liberibacter asiaticus' (CLas), a phloem limited $\alpha$-proteobacteria was identified from symptomatic citrus tree in India (Capoor, 1963; Capoor et al., 1967; Jagoueix et al., 1994). Since then disease has been reported from almost all citrus growing regions of world including Taiwan, Japan, United States, South Africa, North and Central American countries etc. (Brown et al., 2011; Coletta-Filho et al., 2004; Halbert, 2005; Manjunath et al., 2010; Martínez et al., 2009; Matos et al., 2009; Miyakawa and Tsuno, 1989; Oberholzer et al., 1965) and has emerged as major bottleneck to citrus cultivation.

A phloem-limited, gram-negative fastidious, nonculturable bacteria belonging to the genus 'Candidatus $\mathrm{Li}$ beribacter' is associated with the HLB disease of citrus. So far three species of this fastidious bacteria, CLas found in Asian region, Brazil (Sao Paulo) and United States (Florida) (Bove, 2006); 'Ca. Liberibacter africanus' (CLaf) found in African countries (Jagoueix et al., 1994); and ' $\mathrm{Ca}$. Liberibacter americanus' (CLam) found in Brazil and South America (Texeira et al., 2005) are reported. CLas and CLam are vectored by the Asian citrus psyllid (Diaphorina citri) and CLaf by the two-spotted citrus psyllid (Trioza erytreae) (Bové, 2006). The CLaf is heat sensitive and does not cause symptoms at temperatures greater than $25-30^{\circ} \mathrm{C}$. The CLas primarily distributed in Asia, is heat tolerant and able to cause symptoms at temperatures greater than $35^{\circ} \mathrm{C}$ and considered the most destructive one. The CLam appears heat sensitive similar to that of the CLaf (Bové, 2006). CLas bacterium has been found most widespread and devastating due to its wide host range and is able to infect most rutaceae species and some solanaceae species (Halbert and Manjunath, 2004).

Characterization of bacterial strains or genotypes is essentially required for understanding the epidemiological patterns and for devising durable management strategies. Conventionally CLas strains have been characterized based on the most conserved genomic locus (16S rDNA). Due to low genetic variation in the $16 \mathrm{~S}$ rDNA genomic region, it is not ideal target for adequate genetic resolution for categorization of strains or genotypes (Chen et al., 2010; Deng et al., 2008; Jagoueix et al., 1994). Other genomic regions like beta operon, ribosomal protein (rp) and outer membrane protein (omp) genes were alternatively used for characterizations of CLas strains but have limited resolution potential in genetic differentiation of CLas strains (Bastianel et al., 2005; Deng et al., 2008; Hocquellet et al., 1999). Single-nucleotide polymorphism based variations in the omp locus suggested the grouping of CLas popula- tion from China-Guangdong with those from Thailand and Nepal, whereas the strains from Philippines and ChinaBehai were in separate group (Deng et al., 2008). Genetic variations in the alternative loci like bacteriophage-type DNA polymerase revealed three distinct clusters of the CLas population from Southeast Asia (Tomimura et al., 2009). The clustering pattern was not in congruence with the geographical origin of the strains except for those from Indonesia.

Limited genetic variability in the most commonly characterized genetic loci of CLas has further demanded for targeting the variable and hypervariable loci with adequate genetic resolution. Simple sequence repeat or microsatellite markers with variable number of tandem repeats (VNTR) have been widely employed as robust marker in differentiating the bacterial species (Katoh et al., 2011; Lin et al., 2005; Ma et al., 2014). CLIBASIA_01645 loci in the CLas genome was identified and used as a sensitive indicator in differentiation of strains (Chen et al., 2010). This region putatively encodes for bacteriophage repressor protein (Duan et al., 2009), which regulates the phage/prophage activity. The variations in this genomic region could affect environmental adaptations and pathogenicity (Liu et al., 2011). Tandem repeat number (TRN) variations in the bacterial population are generated through DNA strand slippage (Bichara et al., 2006; Verstrepen et al., 2005) and have role in pathogenic or environmental fitness (Boles et al., 2004). TRN profiling has recently been used for fine genetic resolution of CLas population (Chen et al., 2010; Ghosh et al., 2015; Katoh et al., 2011; Ma et al., 2014).

Analysis of genetic diversity is important to understand the ecology and epidemiology of CLas bacterial population. The hilly terrains of North Eastern region of India, known as North Eastern Hill (NEH) region, a rich treasure of citrus diversity has not been surveyed for characterization of CLas strains. Large number of citrus species is grown in this region in wild, semi-wild and cultivated conditions. Unlike other parts of India, where citrus is generally grown as commercial crop and being propagated by budded plants, the citrus planted in North Eastern (NE) region is predominantly of seedling origin. Analysis of genetic diversity is important to understand the ecology and epidemiology of this otherwise genetically homogenous population of CLas bacteria. Hence systematic sampling of HLB infected citrus from this region was undertaken in the present study to unravel the genetic diversity in CLas population prevalent in the North East region of India based on the TRN in the CLIBASIA_01645 locus. The overall genetic profile of CLas population in India has been 
presented.

\section{Materials and Methods}

Samples and bacterial sources. Samples were collected during the period June 2017 to July 2018 from the major citrus groves of NEH region of India, covering the states of Manipur (34 samples), Tripura (6 samples), Nagaland (6 samples), Meghalaya (5 samples), and Arunachal Pradesh (4 samples). Four to five twigs along with leaves were collected from the symptomatic citrus trees (exhibiting the symptoms of HLB) and one tree each from a citrus grove was considered as a strain. As in NEH region of India, the citrus is usually grown on un-terraced hill slopes, an aggregate of citrus plants in an isolated pocket was considered equivalent to one orchard/strain in the present study. The CLas strains were sampled from acid lime (Citrus aurantifolia), mandarin (Citrus reticulata), Assam lemon (Citrus limon), Kachai lemon (Citrus jambhiri), sweet orange (Citrus sinensis), pomelo (Citrus grandis), and Citrus macroptera grown in the surveyed groves (Table 1). Collected samples were brought to laboratory, mid ribs and petioles were excised and stored under deep freezing conditions $\left(-80^{\circ} \mathrm{C}\right)$ till further analysis.

DNA extraction and testing for CLas presence. The midribs and petioles of the collected citrus leaves were used for total DNA extraction using the DNeasy Plant Mini Kit (Qiagen, Hilden, Germany) following manufactures' protocol with $200 \mathrm{mg}$ of the tissues. Initial testing for the CLas presence was done using primer pair CGBF (5'-TGGGTGGTTTACCATTCAGTG-3') and CGBR (5'-CAATGGGTTGCGAAGTCGCG-3') (Datar et al., 2014; Meena and Baranwal, 2016) targeting partial 16S rDNA gene of bacterial genome yielding an amplicon of $\sim 450$ bp.

Amplification of CLIBASIA_01645 genomic locus and sequencing. The CLas positive samples were further used for the amplification of CLIBASIA_01645 locus employing the previously reported primer set, LapGPIf (5'-GACATTTCAACGGTATCGAC-3') and LapGP1r (5'-GCGACATAATCTCACTCCTT-3') (Chen et al., 2010). The PCR reaction was carried out in SimpliAmp Thermal Cycler (Applied Biosystems, Carlsbad, CA, USA) in $25 \mu \mathrm{l}$ mixture containing $100 \mathrm{ng}$ of template DNA, 2.5 $\mu 1$ of $10 \times$ buffer, $1 \mu 1$ of $\mathrm{MgCl}_{2}(25 \mathrm{mM}), 1 \mu \mathrm{l}$ of dNTP $(10$ $\mathrm{mM}), 1 \mu 1$ each of primers $(10 \mathrm{mM}), 0.5 \mu \mathrm{l}$ of Taq DNA polymerase $(5 \mathrm{U} / \mu \mathrm{l})$ and nuclease free water. The thermal cycling conditions were: one cycle of $95^{\circ} \mathrm{C}$ for $4 \mathrm{~min}$, fol- lowed by 35 cycles at $95^{\circ} \mathrm{C}$ for $30 \mathrm{~s}, 58^{\circ} \mathrm{C}$ for $45 \mathrm{~s}, 72^{\circ} \mathrm{C}$ for $1 \mathrm{~min}$ and final extension at $72^{\circ} \mathrm{C}$ for $10 \mathrm{~min}$. The amplicons were electrophoresed in $1.5 \%$ agarose gel and visualized using UV light. Out of the $25 \mu \mathrm{l}$ amplified product, $5 \mu \mathrm{l}$ was used for gel electrophoresis based analysis and remaining $20 \mu \mathrm{l}$ for purification of DNA using QIAquick PCR Purification Kit (Qiagen). The purified single amplicon DNAs were then sequenced directly bi-directionally (Eurofins Genomics India Pvt. Ltd., Bengaluru, India) using ABI BigDye terminator sequencing method. Each amplicon was sequenced twice and the resulting sequences of each amplicon which shared $>99.6 \%$ identity were considered for further analysis.

In silico sequence analysis. The putative identification of the sequenced fragments was initially done using nucleotide BLAST programme of NCBI (https://blast.ncbi.nlm. nih.gov/). The VNTR, referred to as TRN in the CLIBASIA_01645 was calculated using Tandem Repeats Finder software (http://tandem.bu.edu) (Benson, 1999). The tandem repeats obtained in the software were further verified manually. Frequency of different TRN containing CLas genotypes was calculated and differences in the genetic variations were analyzed statistically using $\mathrm{F}$ test employing analysis of variance test (Gomez and Gomez, 1984), where if the computed $F$-value was greater than tabular $F$ value at 5\% level of significance, the differences in the TRN of CLas associated with specific citrus host cultivar was considered significant. In case if the computed $F$-value was lower than or equal to the tabular $F$-value at the 5\% level of significance, the differences in the TRN of CLas associated with specific citrus host cultivar was considered non-significant. Based on the genetic variations in the CLIBASIA_01645 locus, the CLas strains were divided into different classes as defined by Ghosh et al. (2015) with little modification as: class I, TRN $\leq 5$; class II, $5<$ TRN $\leq 10$; class III, $10<\mathrm{TRN} \leq 15$; class IV, $15<\mathrm{TRN} \leq 20$; and class $\mathrm{V}, \mathrm{TRN}>20$. The population genetic diversity among different populations of CLas were calculated using Nei's $\mathrm{H}$ value as $\mathrm{H}=1-\sum \mathrm{pi}^{2}$, where 'pi' referred to as frequency of the allele ' $i$ ' at the locus (Nei, 1973). In order to describe the CLas population structure based on TRN10 threshold, the $\mathrm{R}_{10}$ values were calculated as ratio of TRN $\leq$ 10 and TRN $>10$ genotypes which were stabilized empirically (Chen et al., 2010; Ma et al., 2014).

\section{Results}

Analysis of CLas strains based on TRN in CLIBASIA_01645 locus. PCR amplification using CLIBA- 
Table 1. Analysis of tandem repeat sequence of HLB-associated CLas strains from North East Hill region of India

\begin{tabular}{|c|c|c|c|c|c|c|}
\hline No. & Sample name ${ }^{a}$ & Host plant & Tandem repeat & $\begin{array}{c}\text { GenBank } \\
\text { accession No. }\end{array}$ & $\begin{array}{l}\text { No. of repeat } \\
\text { motifs present }\end{array}$ & Class \\
\hline 1 & $\mathrm{MnH}-1$ & Acid Lime & AGACACA & MH781492 & 4 & I \\
\hline 2 & $\mathrm{MnH}-3$ & Acid Lime & AGACACA & MH781493 & 4 & I \\
\hline 3 & MnH-7 & Acid Lime & AGACACA & MH781494 & 4 & I \\
\hline 4 & MnH-15 & Acid Lime & AGACACA & MH781495 & 12 & III \\
\hline 5 & MnH -19 & Acid Lime & AGACACA & MH781496 & 21 & $\mathrm{~V}$ \\
\hline 6 & $\mathrm{MnH}-21$ & Acid Lime & AGACACA & MH781497 & 4 & I \\
\hline 7 & MnH -22 & Acid Lime & AGACACA & MH781498 & 8 & II \\
\hline 8 & $\mathrm{MnH}-23$ & Acid Lime & AGACACA & MH781499 & 2 & I \\
\hline 9 & $\mathrm{MnH}-24$ & Acid Lime & AGACACA & MH781500 & 5 & I \\
\hline 10 & $\mathrm{MnH}-25$ & Acid Lime & AGACACA & MH781501 & 5 & I \\
\hline 11 & $\mathrm{MnH}-26$ & Acid Lime & AGACACA & MH781502 & 5 & I \\
\hline 12 & MnH -27 & Acid Lime & AGACACA & MH781503 & 5 & I \\
\hline 13 & $\mathrm{MnH}-28$ & Acid Lime & AGACACA & MH781504 & 5 & I \\
\hline 14 & $\mathrm{MnH}-30$ & Acid Lime & AGACACA & MH781505 & 5 & I \\
\hline 15 & $\mathrm{MnH}-31$ & Acid Lime & ACACAAG & MH781506 & 9 & II \\
\hline 16 & $\mathrm{MnH}-35$ & Acid Lime & AGACACA & MH781507 & 8 & II \\
\hline 17 & MnH -36 & Mandarin & AGACACA & MH781508 & 12 & III \\
\hline 18 & MnH -55 & Kachai lemon & AGACACA & MH781509 & 6 & II \\
\hline 19 & $\mathrm{MnH}-56$ & Kachai lemon & AGACACA & MH781510 & 6 & II \\
\hline 20 & MnH -57 & Kachai lemon & AGACACA & MH781511 & 9 & II \\
\hline 21 & MnH -62 & Kachai lemon & AGACACA & MH781512 & 11 & III \\
\hline 22 & MnH -63 & C. macroptera & AGACACA & MH781513 & 6 & II \\
\hline 23 & $\mathrm{MnH}-65$ & Mandarin & AGACACA & MH781514 & 7 & II \\
\hline 24 & $\mathrm{MnH}-66$ & Acid lime & AGACACA & MH781515 & 5 & II \\
\hline 25 & MnH -86 & Assam lemon & AGACACA & MH781516 & 7 & II \\
\hline 26 & MnH -88 & Assam lemon & AGACACA & MH781517 & 5 & II \\
\hline 27 & MnH -91 & Mandarin & AGACACA & MH781518 & 9 & II \\
\hline 28 & $\mathrm{MnH}-93$ & Acid Lime & AGACACA & MH781519 & 4 & I \\
\hline 29 & MnH -94 & Acid Lime & AGACACA & MH781520 & 0 & I \\
\hline 30 & MnH -99 & Acid Lime & AGACACA & MH781521 & 4 & II \\
\hline 31 & $\mathrm{MnH}-101$ & Acid lime & AGACACA & MH781522 & 6 & II \\
\hline 32 & $\mathrm{MnH}-105$ & Acid Lime & AGACACA & MH781523 & 7 & II \\
\hline 33 & $\mathrm{MnH}-106$ & Assam lemon & AGACACA & MH781524 & 7 & II \\
\hline 34 & $\mathrm{MnH}-108$ & Pumello & AGACACA & MH781525 & 7 & II \\
\hline 35 & $\mathrm{NgH}-1$ & Assam lemon & AGACACA & MH781526 & 5 & II \\
\hline 36 & $\mathrm{NgH}-7$ & Assam Lemon & $\begin{array}{l}\text { ACTGTTGTTATCCTGTC- } \\
\text { GATACCGTTGAAATGTC }\end{array}$ & MH781527 & 2 & I \\
\hline 37 & NgH-9 & Assam lemon & AGACACA & MH781528 & 9 & II \\
\hline 38 & $\mathrm{NgH}-10$ & Acid lime & AGACACA & MH781529 & 8 & II \\
\hline 39 & $\mathrm{NgH}-11$ & Sweet orange & AGACACA & MH781530 & 8 & II \\
\hline 40 & $\mathrm{NgH}-12$ & Acid lime & AGACACA & MH781531 & 5 & II \\
\hline 41 & TrH-1 & Acid Lime & AGACACA & MH781532 & 4 & I \\
\hline 42 & TrH-2 & Mandarin & AGACACA & MH781533 & 9 & II \\
\hline 43 & TrH-3 & Mandarin & AGACACA & MH781534 & 9 & II \\
\hline 44 & TrH-4 & Mandarin & AGACACA & MH781535 & 9 & II \\
\hline 45 & TrH-9 & Mandarin & AGACACA & MH781536 & 6 & II \\
\hline 46 & TrH-10 & Mandarin & AGACACA & MH781537 & 6 & II \\
\hline
\end{tabular}


Table 1. Continued

\begin{tabular}{|c|c|c|c|c|c|c|}
\hline No. & Sample name ${ }^{\mathrm{a}}$ & Host plant & Tandem repeat & $\begin{array}{c}\text { GenBank } \\
\text { accession No. }\end{array}$ & $\begin{array}{l}\text { No. of repeat } \\
\text { motifs present }\end{array}$ & Class \\
\hline 47 & MgH-1 & Acid lime & AGACACA & MH781538 & 4 & I \\
\hline 48 & MgH-2 & Mandarin & AGACACA & MH781539 & 6 & II \\
\hline 49 & $\mathrm{MgH}-4$ & Mandarin & AGACACA & MH781540 & 9 & II \\
\hline 50 & MgH-5 & Mandarin & AGACACA & MH781541 & 7 & II \\
\hline 51 & MgH-6 & Mandarin & AGACACA & MH781542 & 7 & II \\
\hline 52 & AnH-5 & Acid lime & AGACACA & MH781543 & 8 & III \\
\hline 53 & AnH-8 & Mandarin & AGACACA & MH781544 & 12 & III \\
\hline 54 & AnH-12 & Mandarin & AGACACA & MH781545 & 9 & II \\
\hline 55 & AnH-13 & Mandarin & AGACACA & MH781546 & 9 & II \\
\hline
\end{tabular}

HLB, huanglongbing; CLas, 'Candidatus Liberibacter asiaticus'.

a Sample with code: $\mathrm{MnH}$, from Manipur $(n=34)$; $\mathrm{NgH}$, from Nagaland $(n=6)$; $\mathrm{TrH}$, from Tripura $(n=6)$; $\mathrm{MgH}, \mathrm{Meghalaya}(n=5)$; $\mathrm{AnH}$, Arunachal Pradesh $(n=4)$.

Acid lime (Citrus aurantifolia), mandarin (Citrus reticulata), Assam lemon (Citrus limon), Kachai lemon (Citrus jambhiri), sweet orange (Citrus sinensis), pomelo (Citrus grandis) and Citrus macroptera.

SIA 01645 specific primers LapGP-1f/LapGP-1r generated a single amplicon of $\sim 650 \mathrm{bp}$ in most of the 55 samples except for a few cases where a larger amplicons up to 700 bp were observed (data not shown). Sequencing of the amplified region and sequence analysis further indicated the variation in the targeted CLIBASIA_01645 loci of respective CLas strains. Analysis of 55 CLas strains characterized in the present study indicated that TRNs at this locus varied from 0 to 21 (Table 1). Interestingly, CLas strains sampled from acid lime in Manipur showed large genetic variations in the CLIBASIA_01645 locus ranging from 0 TRN (strain MnH-94) to maximum TRN of 21 (strain MnH-19). All the CLas strains had tandem repeats of 'AGACACA' sequences except for the strains CLas-NgH-7 (sampled from Assam lemon in Nagaland) and CLas-MnH-31 (sampled from acid lime in Manipur) which had 'TTGTTATCCTGTCGATACCGTTGAAATGTC' and 'ACACAAG' as repeat sequence in the CLIBASIA_01645 locus.

Among the NEH population of CLas, TRN5 and TRN9 were the most frequent (total frequency of $36.36 \%$ ) followed by TRN4 (14.55\%) and TRN6, TRN7 with a frequency of $12.73 \%$ each (Table 2). Interestingly, CLas strains with TRN9 were found in all the NEH states sampled in the present study. Class II type CLas genotypes $(5<$ TRN $\leq 10$ ) had highest prevalence (frequency of $60.00 \%$ ) in the samples characterized in the present study. Class I genotypes was second highest prevalent (29.09\%) in the NEH region.

A demarcation of CLas genotypes of NEH region based on high altitude ( $>500$ meters above mean sea level) and low altitude $(<500 \mathrm{~m}$ above mean sea level) indicated that TRN5 genotypes were more prevalent in high altitude citrus groves (20.51\% frequency) followed by TRN4 and TRN7 (each with a frequency of 17.94\%). In contrast, in the low altitude citrus groves, CLas genotypes of TRN6 were most prevalent ( $42.85 \%$ frequencies) followed by TRN3 and TRN2 at a frequency of $21.42 \%$ and $14.28 \%$, respectively (Table 2). This indicated the altitude based aggregation of CLas genotypes and their preferential accumulation in the citrus groves located at different altitudes.

Mapping of the CLas population from different regions of India based on TRN profiling. The CLas population previously characterized from the other parts of India (Ghosh et al., 2015) were compared with the strains characterized in the present study in order to have overall picture of its genetic structure. In the NE states of India, where citrus is largely cultivated through seedling propagation but budded plants are less commonly planted, the CLas genotypes of TRN7 were more predominant $(23.75 \%$ frequency) followed by TRN5 genotypes ( $15.00 \%$ frequency) (Table 2), which indicated that overall infection of class II genotypes of CLas were widely prevalent in the citrus groves of NE India. Whereas, in the other parts of India, CLas genotypes of TRN5 were most prevalent $(28.57 \%$ frequency) followed by TRN6 and TRN9 (12.50\% frequency for each).

In the NE region, the mandarin was preferentially infected by CLas with TRN7 followed by TRN9 (Fig. 1), whereas in other part of India, they were infected predominantly by TRN5 followed by TRN9 genotypes. Acid lime trees in NE region were predominantly infected with TRN4 and TRN5 CLas (Fig. 1), whereas in rest parts of India, they were infected predominantly by TRN5 CLas genotypes. 


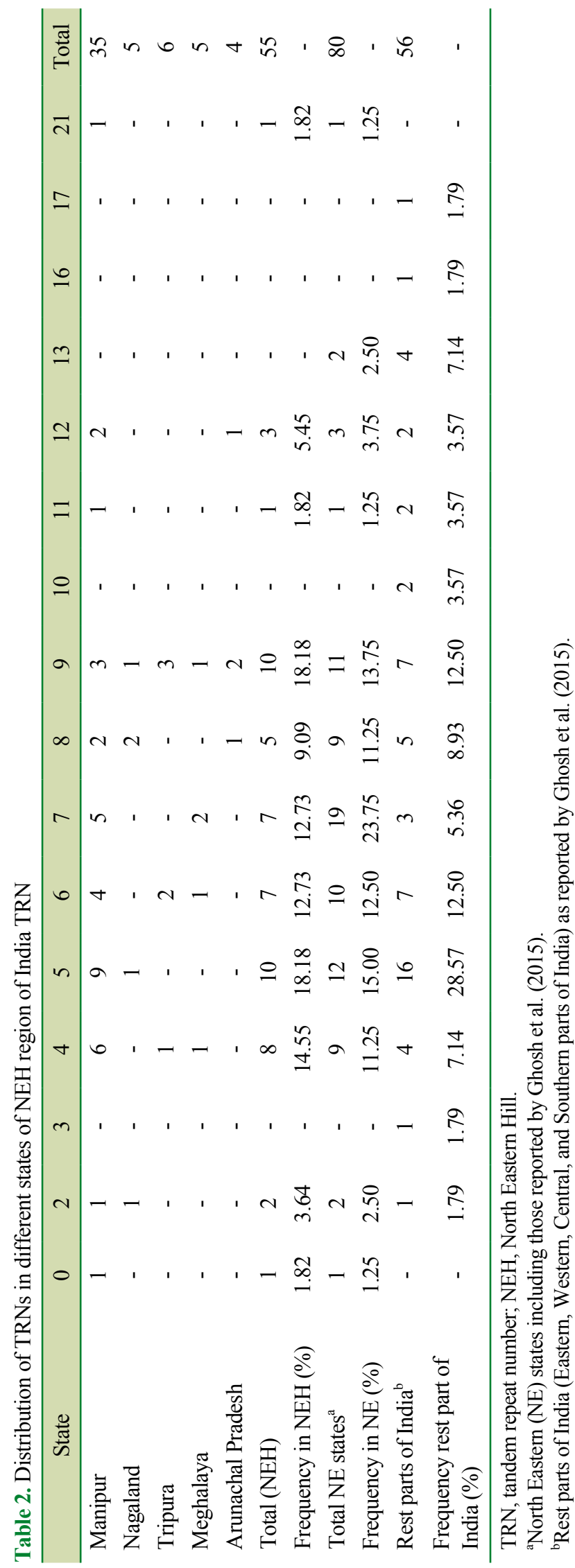

Assam lemons showed highest infection of CLas with TRN7 in the NE region. A strain of rough lemon (Citrus jambhiri) known as Kachai lemon, cultivated in selected pocket of Manipur state showed remarkable diversity of CLas genotypes (TRN4, TRN6, TRN9, and TRN11) although the trees were sampled from a small isolated groves of $4 \mathrm{~km}$ radius, the preferential accumulation of TRN6 CLas was detected (Fig. 1).

TRN typing of CLas strains in the present study along with the previously reported Indian CLas strains from different citrus growing regions was further analyzed for the genetic diversity parameters using Nei's measures $(\mathrm{H}$ values) (Table 3). Among the CLas strains sampled in the present study from NEH states, Manipur CLas strains had maximum H-values (0.86), followed by Nagaland (0.72), Meghalaya (0.72), and Mizoram (0.67) (Table 3), which indicates high genetic diversity in that order. The strains sampled from Tripura, Arunachal Pradesh and Sikkim has $\mathrm{H}$ values in a homogenous range (0.61-0.62), indicating similar patterns of genetic diversity of CLas in these states. The Assam CLas population showed lowest $\mathrm{H}$ values among the NE states (0.58). The ratio of TRN $\leq 10$ and TRN $>10$ genotypes $\left(\mathrm{R}_{10}\right)$ for NE strains was highest (10.43) while for that of North, South and West Indian CLas strains were 5.00, 4.00, and 1.00, respectively (Table 3).

\section{Discussion}

Variations in the TRN in CLIBASIA_01645 genomic loci of CLas have proven to be an important indicator of its genetic diversity and epidemiological studies. TRN in genomic loci like CLIBASIA_01645 is more precise in genetic differentiation of CLas isolates in comparison to single nucleotide polymorphisms (Katoh et al., 2011). The amplification of CLIBASIA_01645 loci of CLas strains from NEH region in present study revealed that all the strains belonged to single amplicon group (SAG) exhibiting identical electrophoretic profile as reported previously (Chen et al., 2010; Ma et al., 2014). Association of specific TRN class of CLas genotype with specific citrus cultivar has been observed e.g. mandarins (Khasi mandarin) were predominantly infected by TRN7 and TRN9 genotypes. In previous study preferential accumulation of TRN5 and TRN9 was reported form mandarins (Ghosh et al., 2015). Sweet oranges in NE region were more frequently infected with CLas of TRN7, whereas preferential accumulation of TRN6 was detected earlier from sweet oranges grown in other parts of India (Ghosh et al., 2015). Acid limes from NE region showed large diversity of CLas genotypes as 


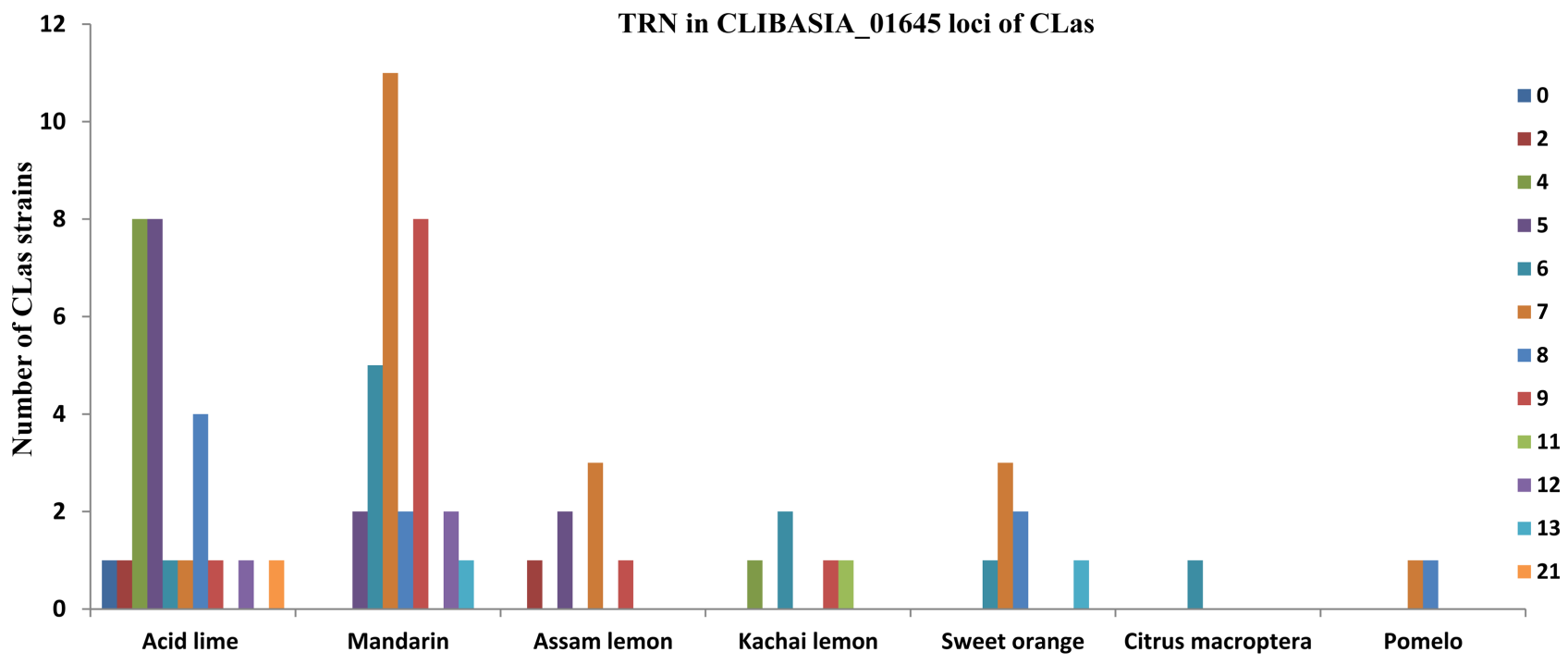

Citrus species

Fig. 1. Graphical illustration of tandem repeat numbers (TRN) distribution in 'Candidatus Liberibacter asiaticus' (CLas) strains sampled from different citrus hosts in North Eastern (NE) India (combined data of present study for hilly terrains of NE India and previous study of Ghosh et al., 2015). Color bars represent number of repeat motifs (different TRN).

TRN0 to TRN21 were detected in acid lime (classes I, II, III, and V) (Fig. 1), which to the best of our knowledge is the widest range of diversity for any single citrus species reported worldwide. Although the TRN specifically varied with the citrus cultivar sampled in the present study, the overall class (i.e., class II) remained same. The differences in the TRN of CLas associated with specific citrus host cultivar were non-significant $(P>0.05)$, as also indicated in the previous studies (Chen et al., 2010; Ghosh et al., 2015). Current study indicated that inter-population TRN distribution in the different citrus groves of India is different. The CLas strains from North East India belonged to SAG as like that of Guangdong and Florida (Chen et al., 2010) unlike that of existence of both SAG and multiple amplicon group reported from Southern China (Ma et al., 2014).

The uniqueness of the genetic profiles of CLas strains from NE region along with the high variability indicated that selection pressure and other evolutionary forces driving the evolution of CLas in this region are quite distinct compared to other parts of the India. Highest frequency of TRN7 and TRN5 CLas genotypes in entire NE region and TRN6 and TRN7 based on the earlier sampling (Ghosh et al., 2015), indicated that HLB-associated CLas population in NE India predominantly belonged to Class II (with TRNs of 7, 5, 6 and 9). CLas with TRN5 were the most commonly associated with the citrus grown in other parts of the country followed by TRN6 and TRN9. Class II $(5<$ TRN $\leq 10$ ) was found most common and widely distrib- uted all over the India. However, TRN7 harbouring CLas strains were specifically aggregated in the citrus growing region of NE India. The class V (TRN21) CLas genotype was detected for the first time from citrus groves in India. Two novel TRN loci with new repeat motifs were also detected from the Assam lemon grown in Nagaland (NgH7) and acid lime grown in Manipur (MnH-31). To the best of our knowledge, these are two novel repeat motifs in CLIBASIA_01645 locus of CLas genome, which might have role in distinct pathogenicity and ecological adaptation. The range of variation in TRN among CLas strains clearly demonstrates that the population of these otherwise genetically homogeneous bacteria is very diverse in India (as evident from the TRN0-TRN21 detected in the present study). A strain of rough lemon (Citrus jambhiri) grown in an isolated remote grove of Manipur for decades together (100\% seedling origin) harboured CLas genotypes with TRN6, TRN9, and TRN11 (class II and class III).

CLas strain with TRN in the class IV has not been detected in the present study but it was reported in sweet orange earlier (Ghosh et al., 2015). The diversity of CLas genotypes indicated diverse evolutionary forces (ecological niche, environmental conditions, psyllid vector prevalence and host diversity niche), which has led to the evolution of diverse genotypes and unique environmental adaptation as evident from the diverse TRN in the CLIBASIA_01645 genomic region.

Nei's H value has been widely used as a genetic param- 
Table 3. Population structures of CLas in different states of North East India and other regions described by Nei's $H$ value and $R_{10}$

\begin{tabular}{|c|c|c|}
\hline Area & $\begin{array}{l}\text { Nei's } \\
\text { H-value }\end{array}$ & $\mathrm{R}_{10}$ \\
\hline Manipur & 0.860 & $10.43(73 / 7)$ \\
\hline Tripura & 0.611 & \\
\hline Arunachal Pradesh & 0.625 & \\
\hline Nagaland & 0.722 & \\
\hline Meghalaya & 0.720 & \\
\hline Sikkim & 0.625 & \\
\hline Mizoram & 0.667 & \\
\hline Assam & 0.580 & \\
\hline North East (total) & 0.861 & \\
\hline Eastern India (West Bengal) & 0.776 & $-(7 / 0)$ \\
\hline Karnataka & 0.800 & $4.00(16 / 4)$ \\
\hline Andhra Pradesh & 0.000 & \\
\hline Tamil Nadu & 0.793 & \\
\hline South India & 0.755 & \\
\hline $\begin{array}{l}\text { North India (Uttar Pradesh and } \\
\text { Uttarakhand) }\end{array}$ & 0.667 & $5.00(5 / 1)$ \\
\hline Madhya Pradesh & 0.444 & $-(13 / 0)$ \\
\hline Vidarbha-Maharashtra & 0.620 & \\
\hline Central India & 0.710 & \\
\hline $\begin{array}{l}\text { Western India } \\
\text { (Northern Maharashtra) }\end{array}$ & 0.860 & $1.00(5 / 5)$ \\
\hline Total overall & 0.874 & \\
\hline
\end{tabular}

The tandem repeat numbers of isolates characterized in the present study and earlier study (Ghosh et al., 2015) were used for analysis of genetic parameters.

CLas, 'Candidatus Liberibacter asiaticus'.

eter for assessing the variability in genomic loci of bacterial population (Katoh et al., 2011; Ma et al., 2014). CLas strains from Eastern and Southern India had H-values in similar range (0.75-0.77), whereas that of North India was the lowest, indicating lowest genetic diversity of the CLas population in this region. Strains from Western India (Northern part of Maharashtra region) showed the high $\mathrm{H}$-values (0.86). The range of variations in $\mathrm{H}$-values was highest among NE states (0.58-0.86) as compared to other regions of India. The variations in the $\mathrm{H}$-values among the characterized citrus groves were significant $(P=0.02)$. This could be possible because of the high variability of citrus species and prevalence of psyllid vectors along with the availability of alternate hosts in this region. Studies from other citrus growing parts of the world also reported the similar extent of genetic variation $(\mathrm{H}$-value in the range of 0.83-0.88) for CLas population in the areas harbouring high genetic diversity in citrus (Central Japan, Southern Ja- pan, Southern China) (Katoh et al., 2011; Ma et al., 2014).

As reported earlier by Ma et al. (2014), although Nei's $\mathrm{H}$ value represents population diversity of CLas, it does not necessarily reflect orderly distribution of corresponding TRN genotypes. Hence $\mathrm{R}_{10}$ values are used to describe the population structure and genotype aggregation based on TRN in CLIBASIA_01645 locus. Analysis based on $R_{10}$ values (ratio of TRN $\leq 10 / T R N>10$ ) indicated that the NE CLas population had $R_{10}$ values (10.48), significantly higher from other regions of India. The higher $\mathrm{R}_{10}$ values of NE population of CLas represent high TRN genotype aggregation. Earlier Ghosh et al. (2015) also indicated that there is possible aggregation in TRN genotype of CLas population in the unique niche of NE India as evident from comparatively high $\mathrm{R}_{10}$ values. The North East India, a geographically locked region with the high genetic diversity of citrus and its relatives, provides suitable niche and environment for evolution of CLas genotypes as reflected by the variations in TRN in CLIBASIA_01645 genomic loci. CLIBASIA_01645 genomic loci putatively encodes for a bacteriophage repressor, a protein which regulates the activity of phage/prophage (Duan et al., 2009). Variations in TRN in this locus were earlier reported to affect the gene translation thereby leading to truncated proteins, which potentially affect the pathogenicity (Chen et al., 2010). In many culturable bacterial species, TRN variations are predicted to have role in ecological adaptations (Zhou et al., 2014). These variations also lead to enhanced survival rate of bacterial populations (Moxon et al., 1994) particularly in case of pathogens like Haemophilus influenza and $H$. pylori (Razin et al., 1998). Through binary switching in transcription and translation, these changes substantially affect the bacterial adaptation under stress conditions (Zhou et al., 2014). The high genetic variation observed in the NE population of CLas as reflected by the TRN typing, suggests that these variation could lead to evolution of different regulatory proteins encoded by these genetic loci and affecting the pathogenic behaviour or citrus-CLas interactions (Ma et al., 2014; Zhang et al., 2011). Changes in the TRN are expected to alter the expressed proteins, their stability and enzyme activity (Lindstedt, 2005; van Belkum et al., 1998) thus putatively affect the biological functions (Chen et al., 2010). The sampling done in the present study was both from naturally grown (wild and semi-wild) citrus plantations and orchards, all of them were of seedling origin and hence it can be concluded that CLas population characterized here was predominantly native to the NE region and evolved here.

In summary, it can be concluded that CLas population infecting different citrus cultivars in NE India are geneti- 
cally diverse and evolved differentially as compared to other citrus growing regions of India where citrus plants are propagated through budwood. The wide variations in the TRN in the variable CLIBASIA_01645 locus has implication in terms of epidemiology and pathogenicity of the bacterial populations. Indian CLas population was largely dominated by Class II TRN-type CLas population. We also hypothesize that CLas population of NE region is native and evolved over longer period of time.

\section{Acknowledgements}

Authors are grateful to the Department of Biotechnology (DBT), Govt. of India for financial support under DBTtwinning project Agri 2015/57 (Grant No. BT/PR16723/ NER/95/264/2015) and Director, ICAR Research Complex for NEH Region, Umiam, Meghalaya for providing necessary lab facilities.

\section{References}

Ahlawat, Y. S. 1997. Viruses, greening, bacterium and viroids associated with citrus (Citrus species) decline in India. Indian J. Agric. Sci. 67:51-57.

Bastianel, C., Garnier-Semancik, M., Renaudin, J., Bové, J. M. and Eveillard, S. 2005. Diversity of "Candidatus Liberibacter asiaticus," based on the omp gene sequence. Appl. Environ. Microbiol. 71:6473-6478.

Benson, G. 1999. Tandem repeats finder: a program to analyze DNA sequences. Nucleic Acids Res. 27:573-580.

Bichara, M., Wagner, J. and Lambert, I. B. 2006. Mechanisms of tandem repeat instability in bacteria. Mutat. Res. 598:144163.

Boles, B. R., Thoendel, M. and Singh, P. K. 2004. Self-generated diversity produces "insurance effects" in biofilm communities. Proc. Natl. Acad. Sci. U. S. A. 101:16630-16635.

Bové, J. M. 2006. Huanglongbing: a destructive, newly-emerging, century-old disease of citrus. J. Plant Pathol. 88:7-37.

Brown, S. E., Oberheim, A. P., Barret, A. and McLaughlin, W. A. 2011. First report of 'Candidatus Liberibacter asiaticus' associated with huanglongbing in the weeds Cleome rutidosperma, Pisonia aculeata and Trichostigma octandrum in Jamaica. New Dis. Rep. 24:25.

Capoor, S. P. 1963. Decline of citrus tree in India. Bull. Natl. Inst. Sci. India 24:48-64.

Capoor, S. P., Rao, D. G. and Viswanath, S. M. 1967. Diaphorina citri Kuway: a vector of the greening disease of citrus in India. Indian J. Agric. Sci. 37:572-576.

Chen, J., Deng, X., Sun, X., Jones, D., Irey, M. and Civerolo, E. 2010. Guangdong and Florida populations of 'Candidatus Liberibacter asiaticus' distinguished by a genomic locus with short tandem repeats. Phytopathology 100:567-572.
Coletta-Filho, H. D., Targon, M. L. P. N., Takita, M. A., De Negri, J. D., Pompeu, J. Jr., Marchado, M. A., do Amaral, A. M. and Muller, G. W. 2004. First report of the causal agent of Huanglongbing ("Candidatus Liberibacter asiaticus") in Brazil. Plant Dis. 88:1382.

Datar, V. V., Chavan, V., Verma, R., Mungekar, D., Gaikwad, P. and Tripathi, S. 2014. Survey and identification of citrus greening bacterium from multiple locations in Maharashtra. $J$. Plant Dis. Sci. 9:60-63.

Deng, X., Chen, J. and Li, H. 2008. Sequestering from host and characterization of sequence of a ribosomal RNA operon ( $r r n)$ from "Candidatus Liberibacter asiaticus". Mol. Cell. Probes 22:338-340.

Duan, Y., Zhou, L., Hall, D. G., Li, W., Doddapaneni, H., Lin, H., Liu, L., Vahling, C. M., Gabriel, D. W., Williams, K. P., Dickerman, A., Sun, Y. and Gottwald, T. 2009. Complete genome sequence of citrus huanglongbing bacterium, 'Candidatus Liberibacter asiaticus' obtained through metagenomics. Mol. Plant-Microbe Interact. 22:1011-1020.

Ghosh, D. K., Bhose, S., Motghare, M., Warghane, A., Mukherjee, K., Ghosh, D. K. Sr., Sharma, A. K., Ladaniya, M. S. and Gowda, S. 2015. Genetic diversity of the Indian populations of 'Candidatus Liberibacter asiaticus' based on the tandem repeat variability in a genomic locus. Phytopathology 105:1043-1049.

Gomez, K. A. and Gomez, A. A. 1984. Statistical procedures for agricultural research. 2nd ed. John Wiley and Sons, New York, NY, USA. 680 pp.

Halbert, S. E. 2005. The discovery of huanglongbing in Florida. In: Proceedings of the 2nd International Citrus Canker and Huanglongbing Research Workshop, eds. by T. R. Gottwald, W. N. Dixon, J. H. Graham and P. Berger, pp. 1-3. Florida Citrus Mutual, Orlando FL, USA.

Halbert, S. E. and Manjunath, K. L. 2004. Asian citrus psyllids (Sternorrhyncha: Psyllidae) and greening disease of citrus: a literature review and assessment of risk in Florida. Fla. Entomol. 87:330-353.

Hocquellet, A., Toorawa, P., Bové, J. M. and Garnier, M. 1999. Detection and identification of the two Candidatus Liberobacter species associated with citrus huanglongbing by PCR amplification of ribosomal protein genes of the $\beta$ operon. Mol. Cell. Probes 13:373-379.

Jagoueix, S., Bove, J. M. and Garnier, M. 1994. The phloemlimited bacterium of greening disease of citrus is a member of the $\alpha$ subdivision of the Proteobacteria. Int. J. Syst. Bacteriol. 44:379-386.

Katoh, H., Subandiyah, S., Tomimura, K., Okuda, M., Su, H.-J. and Iwanami, T. 2011. Differentiation of "Candidatus Liberibacter asiaticus" isolates by variable-number tandem-repeat analysis. Appl. Environ. Microbiol. 77:1910-1917.

Lin, H., Civerolo, E. L., Hu, R., Barros, S., Francis, M. and Walker, M. A. 2005. Multilocus simple sequence repeat markers for differentiating strains and evaluating genetic diversity of Xylella fastidiosa. Appl. Environ. Microbiol. 71:4888-4892. 
Lindstedt, B. A. 2005. Multiple-locus variable number tandem repeats analysis for genetic fingerprinting of pathogenic bacteria. Electrophoresis 26:2567-x2582.

Liu, R., Zhang, P., Pu, X., Xing, X., Chen, J. and Deng, X. 2011. Analysis of a prophage gene frequency revealed population variation of 'Candidatus Liberibacter asiaticus' from two citrus-growing provinces in China. Plant Dis. 95:431-435.

Ma, W., Liang, M., Guan, L., Xu, M., Wen, X., Deng, X. and Chen, J. 2014. Population structures of 'Candidatus Liberibacter asiaticus' in southern China. Phytopathology 104:158162.

Manjunath, K. L., Ramadugu, C., Majil, V. M., Williams, S., Irey, M. and Lee, R. F. 2010. First report of the citrus Huanglongbing associated bacterium 'Candidatus Liberibacter asiaticus' from sweet orange, Mexican lime, and Asian citrus psyllid in Belize. Plant Dis. 94:781.

Martínez, Y., Llauger, R., Batista, L., Luis, M., Iglesia, A., Collazo, C., Peña, I., Casín, J. C., Cueto, J. and Tablada, L. M. 2009. First report of 'Candidatus Liberibacter asiaticus' associated with Huanglongbing in Cuba. Plant Pathol. 58:389.

Matos, L., Hilf, M. E. and Camejo, J. 2009. First report of 'Candidatus Liberibacter asiaticus' associated with citrus huanglongbing in the Dominican Republic. Plant Dis. 93:668.

Meena, R. P. and Baranwal, V. K. 2016. Development of multiplex polymerase chain reaction assay for simultaneous detection of clostero-, badna- and mandari-viruses along with huanglongbing bacterium in citrus trees. J. Virol. Methods 235:58-64.

Miyakawa, T. and Tsuno, K. 1989. Occurrence of citrus greening disease in the southern islands of Japan. Ann. Phytopathol. Soc. Jpn. 55:667-670 (In Japanese).

Moxon, E. R., Rainey, P. B., Nowak, M. A. and Lenski, R. E. 1994. Adaptive evolution of highly mutable loci in pathogenic bacteria. Curr. Biol. 4:24-33.

Nei, M. 1973. Analysis of gene diversity in subdivided popula- tions. Proc. Natl. Acad. Sci. U. S. A. 70:3321-3323.

Oberholzer, P. C. J., von Standen, D. F. A. and Basson, W. J. 1965. Greening disease of sweet orange in South Africa. In: Proceedings of the 3rd Conference of the International Organization of Citrus Virologists, ed. by W. C. Price, pp. 213-219. University of Florida Press, Gainesville, FL, USA.

Razin, S., Yogev, D. and Naot, Y. 1998. Molecular biology and pathogenicity of mycoplasmas. Microbiol. Mol. Biol. Rev. 62:1094-1156.

Texeira, D. C., Ayres, J., Kitajima, E. W., Danet, L., JagoueixEveillard, S., Saillard, C. and Bové, J. M. 2005. First report of a huanglongbing like disease of citrus in São Paulo State, Brazil, and association of a new Liberibacter species, 'Candidatus Liberibacter americanus', with the disease. Plant Dis. 89:107.

Tomimura, K., Miyata, S.-I., Furuya, N., Kubota, K., Okuda, M., Subandiyah, S., Hung, T.-H., Su, H.-J. and Iwanami, T. 2009. Evaluation of genetic diversity among 'Candidatus Liberibacter asiaticus' isolates collected in Southeast Asia. Phytopathology 99:1062-1069.

van Belkum, A., Scherer, S., van Alphen, L. and Verbrugh, H. 1998. Short-sequence DNA repeats in prokaryotic genomes. Microbiol. Mol. Biol. Rev. 62:275-293.

Verstrepen, K. J., Jansen, A., Lewitter, F. and Fink, G. R. 2005. Intragenic tandem repeats generate functional variability. Nat. Genet. 37:986-990.

Zhang, S., Flores-Cruz, Z., Zhou, L., Kang, B.-H., Fleites, L. A., Gooch, M. D., Wulff, N. A., Davis, M. J., Duan, Y.-P. and Gabriel, D. W. 2011. ' 'Ca. Liberibacter asiaticus' carries an excision plasmid prophage and a chromosomally integrated prophage that becomes lytic in plant infections. Mol. Plant Microbe Interact. 24:458-468.

Zhou, K., Aertsen, A. and Michiels C. W. 2014. The role of variable DNA tandem repeats in bacterial adaptation. FEMS Microbiol. Rev. 38:119-141. 